Irish Math. Soc. Bulletin

Number 76, Winter 2015, 25-26

ISSN 0791-5578

\title{
THEORETICAL AND NUMERICAL ANALYSIS OF RIGID-BODY IMPACTS WITH FRICTION
}

\author{
SHANE J. BURNS
}

This is an abstract of the $\mathrm{PhD}$ thesis Theoretical and Numerical Analysis of Rigid-body Impacts with Friction written by S. Burns under the supervision of Petri Piiroinen at the School of Mathematics, Statistics, and Applied Mathematics, National University of Ireland, Galway and submitted in September 2015.

This thesis gives a flavour of the area of rigid body impacts with friction, an area which has far reaching applications in engineering, sports science and every day life. The focus of this work will be on the two main streams of this field, theoretical and numerical. This thesis will present an overview of the general subject of rigidbody impact, including discussion and analysis of the validity of ones choice of impact law and the numerical techniques required for the simulation of rigid-body impacting systems.

Two impact laws will be introduced in Chapter 3 and a direct comparison will be made in order to examine the varying dynamics that can be achieved using both a basic and a complex impact law and to explore some of the problems that can occur with a more basic formulation. It will be demonstrated that for certain regions in parameter space the two formulations are equivalent, however, for many other regions the two formulations can vary greatly.

A hybrid event-driven numerical scheme is one in which smooth dynamics are described by differential equations, which can be solved numerically using standard techniques, and non smooth events which are described by maps. In Chapter 5, a hybrid event-driven numerical scheme for the implementation of the Energetic Impact Law

2010 Mathematics Subject Classification. 70Exx, 65Pxx.

Key words and phrases. Impact with friction, Nonsmooth, Bifurcation.

Received on 15-12-2015.

SB wishes to acknowledge the economic support from the National University of Ireland, Galway through a scholarship in applied mathematics. 
described in Chapter 3 is presented. Moreover, the framework necessary for the long term simulation of mechanical systems with impacts and chatter is derived.

This thesis also gives an overview of the phenomena known as the Painlevé Paradox in Chapter 6 and presents a numerical experiment to show the occurrence of the paradox for a mechanical system.

\section{REFERENCES}

[1] Burns, S. J. and Piiroinen, P. T.: Simulation and long-term behaviour of unconstrained planar rigid bodies with impact and friction. International Journal of Nonlinear Mechanics. 2015.

[2] Burns, S. J. and Piiroinen, P. T.: The complexity of a basic impact mapping for rigid bodies with impact and friction. Journal of Regular and Chaotic Dynamics. 2014.

(from September 2011) School of Mathematics, Statistics And Applied Mathematics, National University of Ireland, Galway

E-mail address, S. Burns: shane.burns111@gmail.com 